\title{
Novel Way of Using Mobile Phone for an Outside Science Learning Activity
}

\author{
T.M.S.S.K.Y. Ekanayake ${ }^{1}$, K.B. Samarakoon ${ }^{2}$, S.D.K. Wijesundera ${ }^{1}$ \\ ${ }^{1}$ Department of Education, University of Peradeniya, Sri Lanka \\ ${ }^{2}$ Department of Computer Engineering, Faculty of Engineering, University of Peradeniya, \\ Sri Lanka
}

\begin{abstract}
Present-day mobile phones combine the capabilities of communication devices, cameras and computers. Even though their educational values are well established, their widespread use is hindered by the general fears about students' misuse of mobile phones and other barriers such as their operating cost and teachers' inexperience of using them. As a solution to circumvent the barriers of using mobile phones, in this study a set of mobile phones which is connected in a private network using Wi-Fi is considered. An IT application that can be used to manage the private network was developed. A lesson was conducted outside the classroom. Both students and teachers agreed that the mobile phones in a private network supported the outside learning activity and provided a novel learning experience.
\end{abstract}

\section{Introduction}

Researchers and educationists have been widely acknowledge the potential of mobile devices such as mobile phones, smart phones, palmtops and handheld computers (personal digital assistants (PDAs) and tablet PCs) in enhancing the effectiveness of teaching and learning. During the last few decades, identification of a range of possibilities provided by mobile devices for teaching and learning has led to the emergence of a new concept called mobile learning (m-learning). They add an extra dimension to the use of technology in teaching and learning [1]. Further the integration of modern methods and techniques in m-learning helps the learning process more interesting, interactive and also widely available and flexible [2]. References [3] and [4] conclude that mobility and portability provided by these devices have the potential for making access to information and interaction more effective.

Considering the educational potential of mobile devices, reference [5] states that mobile devices add new educational opportunities because they are personal, portable and permit new forms of interactions among all involved in the learning process and their respective surrounding environment. This situation would be enhanced due to one of the main benefits of m-learning to improve students productivity by making knowledge and learning available anytime and anywhere. This feature enables learners to participate in learning activities without the traditional place and time restrictions [6]. Furthermore, the mobile phone allows the learner to learn autonomously [7] and collaboratively [8]. As pointed out by [6], mobile technology provides technical support for discussion based cooperative learning, and it optimizes the learning effect. It also provides opportunities to conduct learning exercise outside the teachermanaged classroom [9, 10] by expanding learning beyond the four walls of the classroom and thus allowing new interactions with the real world [11].

Amongst mobile devices, PDAs and mobile phones are the most commonly used technologies for m-learning [9]. Besides, reference [12] states that mobile phones have been considered as the most successful technology for m-learning. Furthermore, Marriott [13] goes so far as to state that present-day mobile phones are complete multimedia centres that combine the capabilities of a still camera, a video camera, a personal organizer and a web browser in one device. Due to these mobile devices can create a learning environment that provides seamless learning [14]. Mobile devices are cheaper than desktop computers or laptop computers [15], and have a less expensive method of internet access [2]. Moreover, reference [15] also states that mobile devices require less technical support than that is required for computers and laptops. Emphasizing the possibilities of introducing mobile phone as a learning tool, reference [16] states that the learning curve of a mobile phone is very short and therefore it is easier to start using mobile phones and PDAs rather than laptop computers. One reason they point out is that the mobile phone menus are designed with icons and 
text descriptions that help anyone to identify the functions easily. Further the device must be capable of presenting learning content and providing wireless two-way communication between teacher(s) and student(s) [6].

Even though mobile phones have a potential to enhance the teaching and learning process, there are incidents reported in the literature where the mobile phone is considered a threat to the teaching and learning process. For example, the Scottish Qualifications authority points out in [17] that the allegations of cheating have increased in schools because students use their mobile phones to store notes. Further, in India, the Maharashtra Government has banned the use of mobile phones in public and private schools up to class 10 across the state ([18]). In 2008 after a few suicidal incidents related to school students using mobile phones, Sri Lankan Government (where this study was conducted) banned the use of mobile phone in schools.

Considering the potential of mobile phone for bringing the outside world into the classroom and possible issues that could emerge due to mobile phone use especially outside the classroom, this study presents a novel approach of using mobile phone for an outside science learning activity. Here a set of mobile phones is used which is connected to a wireless local area network (WLAN), commonly referred as Wi-Fi. The phones used in this network neither have a SIM (Subscriber Identity Module) nor contract with a commercial cellular company.

\section{Mobile phones for outside science learning activities}

A number of studies are reported in the literature in which the potentials of the mobile phone to bring 'the outside world' into the classroom are highlighted.

Reference [19] reported a study where probes connected to handheld computers that were used to determine the water quality in a river. In this study, each student took measurements using a probe at different points along the stream bed. The students combined their data by sending it to a common personal computer. Then they used their handheld devices to analyze this data and to prepare graphs of combined data sets.

Reference [20] reported a study where school students (aged 13-15) used mobile sensors to collect scientific data in their local areas. These students were provided with a data logger with a set of environmental sensors (probes) and a mobile phone with sound sensor software connected via Bluetooth to a GPS unit. Students took turns to take a set of data collection equipment with them on their journeys from home to school. They collected data on carbon monoxide (CO) levels, sound and temperature. The students also used mobile phone video and image capture to produce a 'snapshot' of the conditions they had experienced. Upon their return to the classroom, data were downloaded onto a personal computer. This activity allowed students to collect, visualize and discuss their own scientific data more effectively than was customary.

Moreover, mobile devices can be used to connect what students learn outside the classroom with classroom learning. Evidence for this is provided by reference [21]. This study addressed the importance of the connection between preparation prior to the school museum visit, the visit itself and follow-up in the classroom. The day before the museum visit, the teacher introduced the lesson and gave out worksheets that students could follow in the museum. During the museum visit, students were loaned a mobile phone, which could access a webbased client. The students in pairs used this camera function of the mobile phone to capture images and sound recordings, add comments and notes and send them to the MyArtSpace website. Later in the classroom, they prepared PowerPoint presentations using the images and created online galleries on the MyArtSpace website. According to the findings of this study, this activity met the expectations of teachers and students and supported curriculum topics in literacy and media studies, enhanced student engagement and bridged the gap between the museum visit and the classroom learning.

References [22] and [23] reported two studies where mobile phones were used for outside science learning activities. In one study, the mutual relationships between organisms and the environment were investigated using a lesson of 80 minutes duration for Grade 11 students. The students in groups examined four locations in the school garden and captured images using the mobile phones provided to them. Upon returning to the class each group sent five images taken from their assigned locations to the teacher's computer using Bluetooth. Then each group presented their findings based on pictures that they sent to the teacher's computer. In the other study, the students went in groups to the school garden and collected the images of the leaves using mobile phones. Based on the images they had in their mobile phones, each group constructed a dichotomous key and presented it to the class. After each presentation, the teacher pointed out the important facts to note. The results show that the images from mobile phone supported to bring the outside world into the classroom, for delivering instructions, for assessing students' learning and for correcting students' misconceptions.

\section{IT environment and private network}

A laptop computer with Application software was configured to run as a web server. The private network was formed by connecting the computer 
with five mobile phones through a router. The teaching and learning IT environment have Applications for teachers to organize the lesson and monitor the lesson while students are carrying out an outside activity. Students can remotely login to the computer and run an Application that gives step-bystep instructions, both with visuals and audio, to carry out the lesson.

This IT environment enables teacher to setup the learning activity by embedding the required pictures, sound files, videos and texts. Then the teacher can run the activity to see whether the activity is organized in the manner wanted by the teacher. Upon setting up the lesson, teacher can assign a lesson to student groups. Figure 1 shows the Application that teacher used to assign a lesson to student groups. Finally, students can login to the lesson and follow the instruction provided. While students are carrying out the learning activity, the teacher can monitor their progress.

\section{Learning activity}

The unit on 'Grafting' from the grade 9 science curriculum was selected as the lesson for this activity. The traditional way of teaching this lesson was, as the first author experienced when she was a student, the teacher introduced the lesson on 'grafting' using the lecture method while using appropriate diagrams. Then the grafting was demonstrated in the school garden by the teacher for all students. Finally, the students were asked to practice at their home garden. Subsequently, when the first author became a teacher, she has introduced the lesson in a similar manner but gave a handout that carried step-by-step instructions with all the necessary diagrams to make the home exercise more effective. In this study, a novel technique was used where mobile phones were used to provide step-bystep instructions for students to carry out the outside activity. First of all 30 minutes training session was provided to students to get familiarize with the particular type of mobile phone used for the activity. Furthermore, in this session the IT environment was also demonstrated to the students. Research team and the teachers who conducted the lesson provided this training. Then the teacher did an introduction to the lesson while relating the concept of 'grafting' to students' day-to-day lives. The teacher used a PowerPoint presentation when doing this. Then teacher did a comprehensive demonstration on grafting while connecting students by questioning at each step of grafting. After that the students were grouped, provided handout in order to do the grafting activity as an outside learning activity while using the mobile phones. Different roles, such as group leader, assistant leader, photographers, instruction reader, developer and assistant developers (according to the teacher this had been done on the previous day) were assigned to each member of the group. Each group was provided two smart phones and they were assigned a specific location in the school garden to engage in the learning activity. A file containing a worksheet and instructions to carry out the leaning activity as well as on the use of mobile phone were given to the groups. Then teacher gave a briefing on the activity, and reminded the responsibilities and role of each player and asked to complete the group activity during the allocated time period.

By receiving the worksheets, students were asked to read and comprehend what need to be done as groups. Then each group started their activity at the assigned area in the school garden. First, student groups took the mobile phones to the field and logged into the IT Application developed while following the instructions. This Application helped them to follow the step-by-step instructions to carry out grafting exercise by themselves. Figure 2 gives some pages of these instructions. These instructions were given with teacher's own voice thus making them to follow the instructions easily.

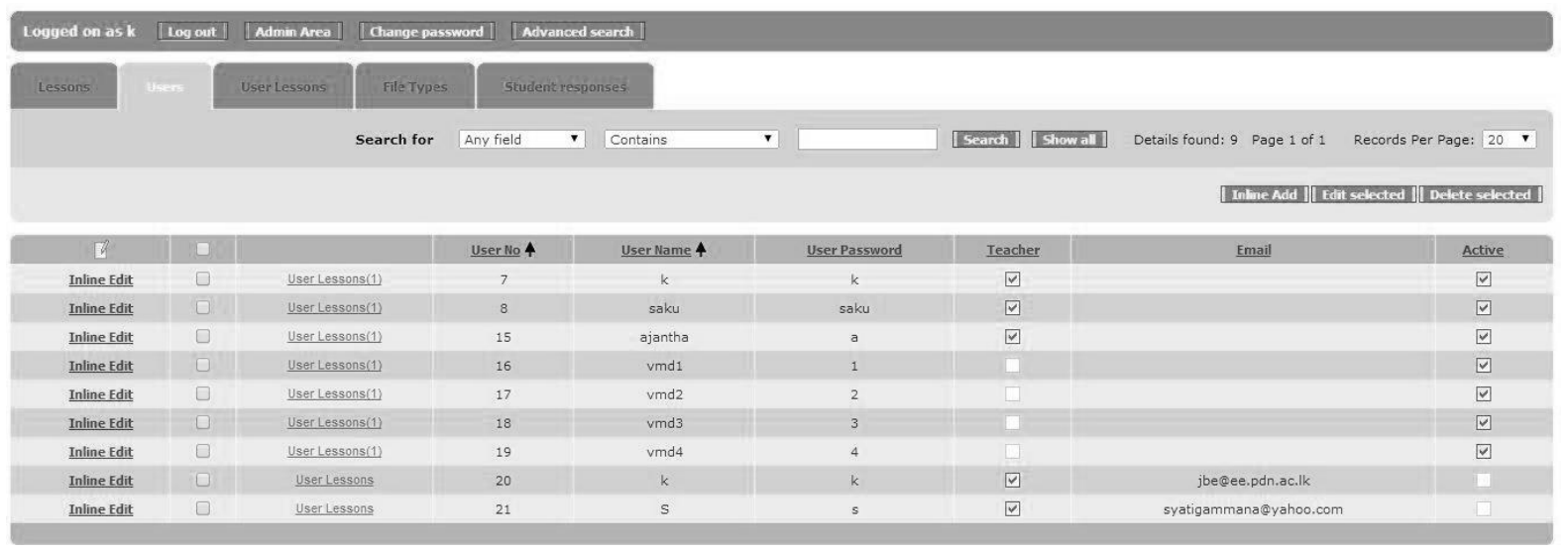

Figure 1: Application to assign a lesson to student groups 

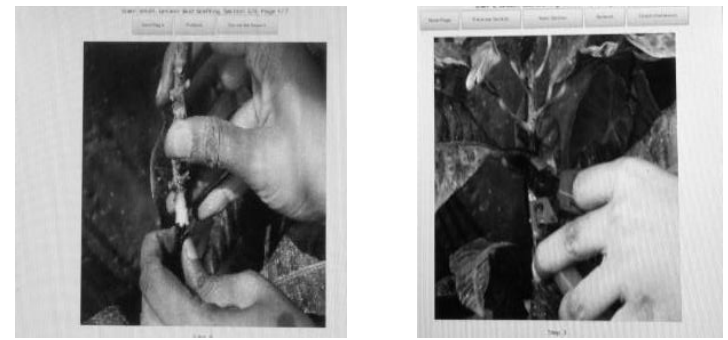

Figure 2: Step by step instructions given through mobile phone

Figure 3 shows how students have carried out this lesson in the school garden. Twenty students participated for this activity in groups of four. Before starting the activity all members tried to clarify the task they were assigned by reading the worksheet and going through the mobile phone application.

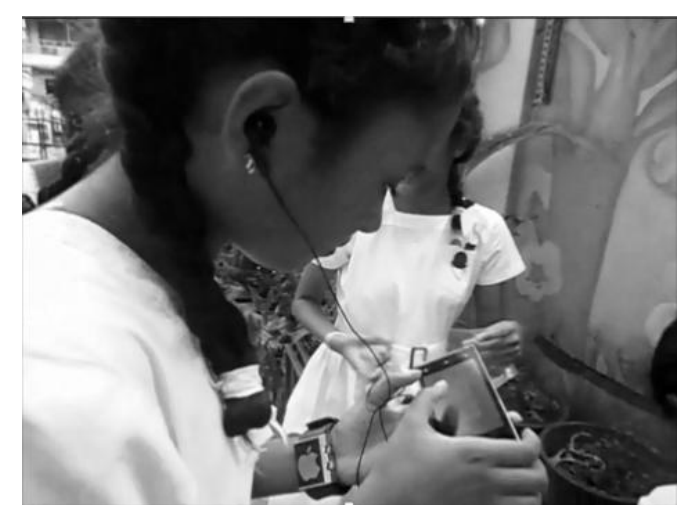

Figure 3: Students carried out the lesson following the step-by-step instructions given through mobile phone

While the students were carrying out the activity, the teacher monitored the activities through her laptop computer while using the IT Application shown in Figure 4. This system enabled teacher to check whether the students are following the steps of the activity. For instance after some steps, the students were asked to (the instruction was appeared on students' mobile phone screen) report the progress by sending a text message (as an answer for the question) or a picture taken from their activity (the output of particular step they proceeded) to the teacher. After examining these pictures, the teacher allowed the students to proceed to the next step. Figure 5 shows the instructions appears on the mobile phone instructing students to upload a picture (this screen was supplemented by a handout provided to them). Upon uploading the image, the teacher observed it on the computer and allowed students to continue the activity

\section{Data collection and analysis}

The data from this study was collected using observations, field notes and the written comments of the participants. Observation was the main data collection method, which was used to gather students' and teacher's voices and activities as both video and audio data. Furthermore, field notes were taken down.

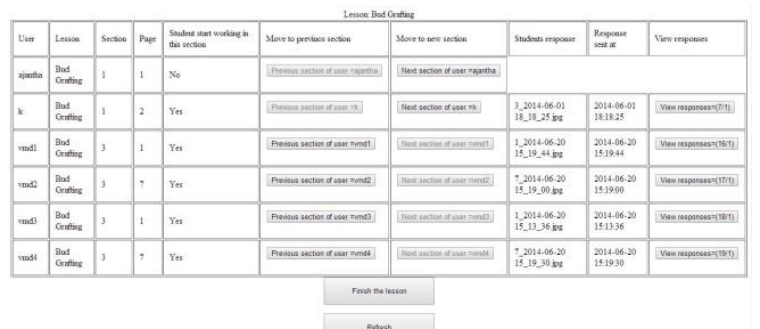

Figure 4: Application to monitor the students' learning activity

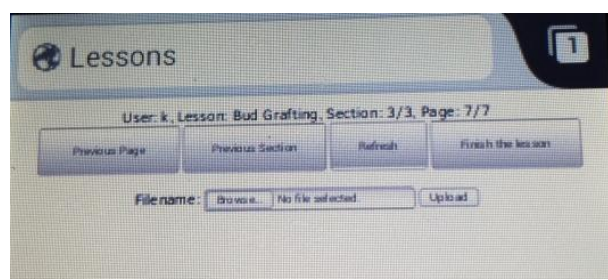

(a) Upload instruction appears in students' mobile phone Gobso User: vmd4, Lesson: Bud Grafting,

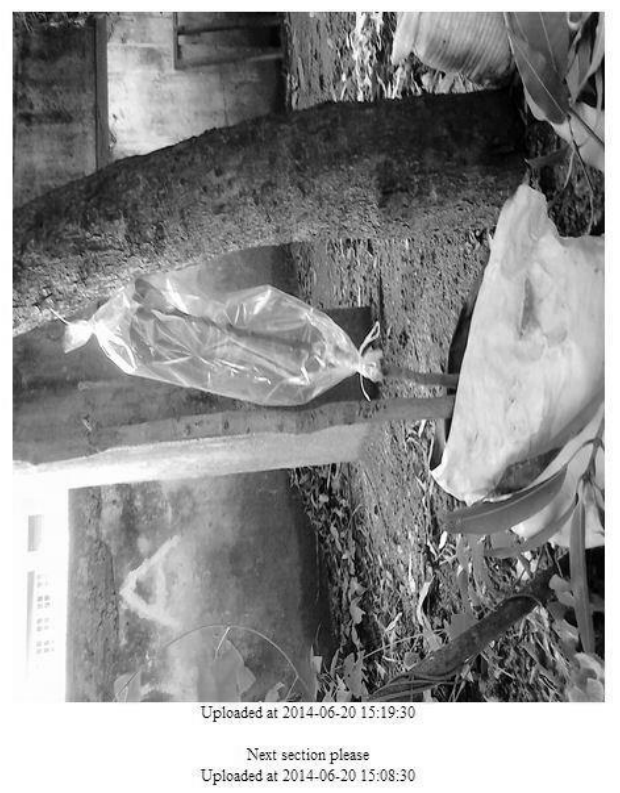

(b) A picture uploaded by students

Figure 5: Monitoring students' progress 
The collected data were analysed using thematic analysis techniques with the support of NVivo10 qualitative data analysis software. First, field notes were computerised, saved as MS Word files and then uploaded them to NVivo10 software. Then all the video and audio files were uploaded into the NVivo10 software and transcribed and translated.

After reading the MS Word files, transcribed video files and the audio files a set of codes were derived and 'free nodes' were developed in NVivo10 software to represent the codes. Next using these 'free nodes', the word files and transcribed data were splitted into meaningful segments. All the text segments under each free node were read again and again and the salient and common three themes were identified.

They are:

1. Outside learning activity supported by the mobile phones in a private network provided opportunities for collaboration and enhanced students' learning.

2. The mobile phones in a private network supported outside learning activity.

3. Developed IT Application provided a novel experience for teacher and students

\section{Findings}

Theme 1: Outside group learning activity supported by the mobile phones in a private network, provided opportunities for collaboration and enhanced students' learning.

It was observed how much students love to engage in learning activities as small groups outside the classroom. For instance after hearing the teacher's words as "today as small group you are going to do a practical work on grafting in the school garden and you are going to use mobile phones during your activity”, students looked at each other with smiley faces.

Firstly, according to teacher's instructions each group assigned roles to engage in the activity as group leader, photographers, instruction readers, and reporters. This enabled students to actively engage in the activity while collaborating with one another (see Figure 6). Asking questions about the activities from each other was a common observation and the ones who had understood the activity better gave explanations.

It was also noted that as the students worked as small groups they could share their knowledge, skills as well as attitudes. For instance in one group when a student was trying to do a cut on the scion the following dialogue was noted:

Student 1: $\quad$ if I do the cut in this way is that ok? Student 2: No no teacher asked to do it as a slant cut.
Student 3: Yes, then the area of the cut easily goes into the rootstock.

Student 2: $\quad$ Not only that a larger surface area supports to fixed the scion with the rootstock.

After the clarification one students demonstrated how the knife and the scion should hold in order to do the cut. Figure 6 shows how all members collaborated to do the cut.

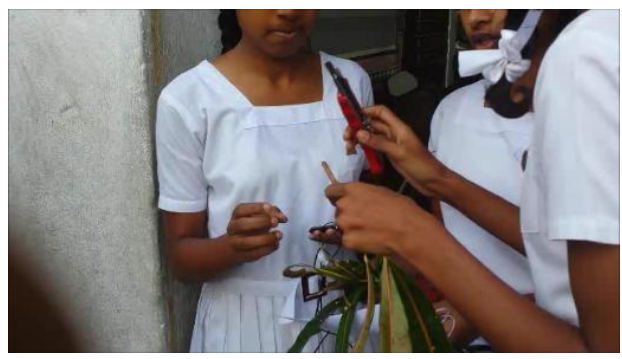

Figure 6: Students actively engaged in the activity in a collaborative manner

It was also observed that the outside group activity provided opportunity to enhance the skills of many members of the group by taking turns while doing the activity. For instance during the learning activity, listening to the audio clip and describing it was done by different members of the group at different times. Furthe, different members were involved when taking photographs during some steps. More interestingly, as the group members wanted to send a quality picture to the teacher's computer via the network it was noted that they themselves assessed the quality of different photographs and selected the best to uploaded to the server (the computer that carried the IT Application).

Moreover, it was observed that engaging in the group activity enhanced students' interactions. For example as the group activity created a safe learning environment the students tended to questioning from each other regarding different matters of the activity.

Moreover, it also found that the working as a group, removed the students' fear to use a new technology in the learning activity. One student expressed her views as follows:

"I do not have a mobile phone with a touch screen. So earlier during the practicing session I was bit fear to use it. However, because I worked with my friends they helped me to use the mobile phone for this activity"

(Student's comments)

One student's written comment is given in Figure 7. This comment says,

"We did today's activity collaboratively. As mobile phone guided us, we managed to do the activity easily. We learned this activity so that we will not forget it forever. We changed the roles 
and carried out the activity successfully. One reason for this success was the collaborative learning environment provided by this system."

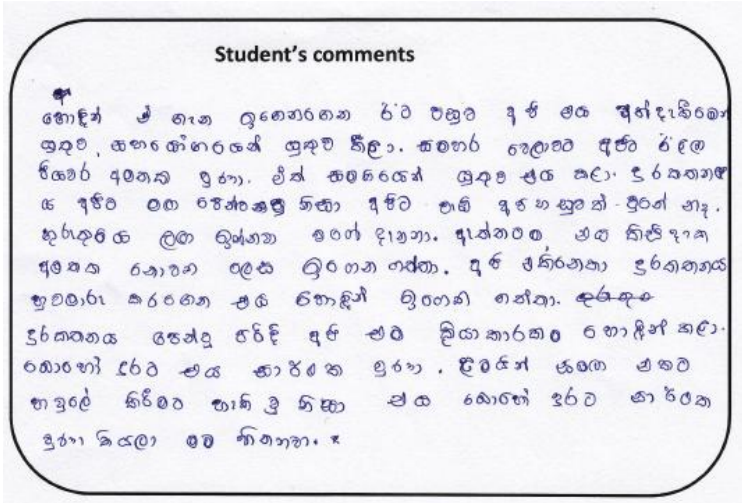

Figure 7: One students' comment (in Sinhala language)

\section{Theme 2: Mobile phones in a private network supported outside learning activity}

"I like the experience I had during today's science lesson on grafting. I saw how the students enthusiastically engaged throughout the lesson. They were so active. The main difference today was the use of mobile phones mmm...mmm particularly as they were in a private network"

(Teacher's comments)

The above was the teacher's words when she was asked about her feelings about the lesson she conducted.

The teacher's appreciation on the support provided by the mobile phones to this outside learning activity was also highlighted in the collected data:

"The use of mobile phones in a private network supported today's outside group learning activity in a new way. One of the fears we had was the possibility of misusing the mobile phones as students could use them to talk to others and browse the Internet. However the SIM free phones provided to the students facilitated the learning activity as such I am with them while taking off the fear we had."

(Teacher's views)

As far as students' learning is considered, since the students could listen and visit the instructions more than once (using the mobile phone by touching 'previous' and 'next' buttons on the screen), mobile phones provided an added value to the outside learning activity. Without the novel learning environment facilitated through the mobile phone in the private network, students had to come to the teacher a number of times to clarify and inquire about steps involved in the activity.
Students also admire the support provided by the mobile phone. One student said:

"Usually our teacher provides an instruction sheet to carry out such an activity. Today, we managed to get instructions with pictures and teacher's voice so that we felt that teacher is with us. It was easy for us to follow the instructions, as they were clear. We managed to listen to the instruction over and over again so that this system facilitated our learning activity."

(Student-2's comments)

\section{Theme 3: Developed IT Application provided a novel experience for teacher and students}

As a fact of using the mobile phone together with the IT Application instructions for this outside learning activity was provided in a unique way. For instance, teacher used texts, audio and colourfull pictures when providing instructions.

Furthermore, it was noted that as this Application provided instructions in a sequential manner, the student groups could carry out the activity in more relaxing environment. The following statement from a student provides evidence for this:

"as we received the instruction one by one we haven't felt that we need to carry out a long list of activities. Instead we could accomplish the given task in a relax way"

(Student-2's comments)

It was also observed that this IT Application made the teacher freere in this lesson than the other lesson. The teacher's expression provides evidence for this.

"as the instruction were provided and managed by the IT Application, I was not too busy as in the usual lessons"

(Teacher's comments)

Furthermore, the data showed that the use of this unique system provided the potential of accessing the students learning specially in outside learning activity. For instance after carrying out a number of steps students had to upload their output (image or text) to the IT Application. These images and text were assessed by the teacher and allowed students to go to next step. Teacher stated her experience on this as follows:

"and the other thing is the possibility of assessing students by checking what student had sent to my computer through their mobile phone in a private network during the lesson itself as well as when it is convenient to me".

(Teacher's comments) 


\section{Discussion and Conclusions}

The mobile phones on a private network have not only facilitated the lesson, but also introduced a novel technique where mobile phones could be used in a safe manner.

Mobile phones on a private network facilitated the outside learning activity on grafting by providing instructions with both visuals and voice and providing means of interactions and feedback. These are unique features offered by the mobile phones connected to the developed IT Application through a private network. Without this system the instructions could not be delivered to students in such an effective way. Further, the mobile phones on the private network supported the teacher to monitor the learning activity effectively as students are displaced and reaching all the groups at a regular interval is not that easy. Since the mobile phone was on a private network and was without the SIM, any fear that teachers had about the misuse of mobile phones also was taken off.

Some problems/limitations of this novel learning environment were also identified. As the teacher had to stay with the computer, she could not be with the student groups. Further the screen size of the mobile phones and background noise were obstacles to follow the audio and video instructions provided to students clearly. Furthermore, some students complained that they could not contact the teacher when they needed.

\section{Acknowledgement}

The National Research Council of Sri Lanka for providing funds through the research grant 12-025

The teachers and the students who participated in the workshops and lesson implementation.

\section{References}

[1] Kukulska-Hulme, A., Introduction, in mobile learning :a handbook for educators and trainers, A. KukulskaHulme and J. Traxler, Editors. 2005, Routledge: Oxon. p. 1-6.

[2] Sarrab,M. and Elgamel,L. Mobile learning (m-learning) and Educational environments. International Journal of Distributed and Parallel Systems (IJDPS), 2012. 3(4).

[3] Moura, A. and A.A. Carvalho. Mobile learning: teaching and learning with mobile phones and Podcasts. in Eighth IEEE International Conference on Advanced Learning Technologies. 2008. Portugal.

[4] Scanlon, E., A. Jones, and J. Waycott, Mobile Technologies: Prospects for their Use in Learning in Informal Science Settings. Journal of Interactive Media in Education, 2005. 25.
[5] Arrigo, M. and G. Ciprì, Mobile Learning for All. Journal of the Research Center for Educational Technology, 2010. 6 (1).

[6] Jiugen, Y., et al. Applying Research of Mobile Learning Mode in Teaching. International Forum on Information Technology and Applications, 2010.

[7] Callum, K.M. and Kinshuk. Mobile Technology in Facilitating Learning Goals. inmLearn 2006 2006. Banff, Canada.

[8] Eliasson, J., et al. Get the bees away from the hive: balancing visual focus on devices in mobile learning. in IADIS Mobile learning 2010. 2010. Porto, Potugal.

[9] Naismith, L., et al., Literature Review in Mobile Technologies and Learning, in Futurelab. 2004.

[10] Corbeil, J.R. and M.E. Valdes-Corbeil, Are You Ready for Mobile Learning? Educause Quarterly online Journal, 2007. 30(2): p. 51-58.

[11] Van 'tHooft, M. and K. Swan, Ubiquitous computing in education: Invisible technology, visible impact. 2007, Mahwah: Erlbaum.

[12] Markett, C., et al., Using short message service to encourage interactivity in the classroom. Computers \& Education, 2006. 46(1): p. 280-293.

[13] Marriott, M., Use this phone to find a date.-Or see video. Or even talk, in New York Times. 2005.

[14] Schmitz,B., et al., Attuning a mobile simulation game for school children using a design-based research approach. Computers \& Education. 2012.

[15] Dawson, D., Handheld technologies for mobile learning 2007, London: latimer Trend.

[16] Csete, J., Y.H. Wong, and D. Vogel. Mobile devices in and out of the classroom. in World Conference on Educational Multimedia, Hypermedia and Telecommunications 2004. Switzerland.

[17] Anonymous. (2007). Mobile mania: Why ban the mobile phone. Learning and Teaching Scotland Retrieved 28/07, 2008, from http://www.ltscotland.org.uk/ connected/articles/16/mobilemania/index.asp

[18] Anonymous. (2009, 21 Feb). Maharashtra govt bans mobile phones in schools. Times of India.

[19] Vahey, P. and V. Crawford, Palm Education Pioneers Program: Final evaluation report. 2002, SRI International: Menlo Park.

[20] Woodgate, D. et al. Mobile Learning in Context: School Science Data Collection as Legitimate Peripheral Participation? inMlearn 2008. Wolverhampton.

[21] Sharples, M., Lonsdale, P., Meek, J., Rudman, P., \& Vavoula, G. (2007). An evaluation of myartspace: A mobile learning service for school museum trips. mLearn 2007, Melbourne, Australia. 
[22] Ekanayake,T.M.S.S.K., Wishart, J.(2014). Developing teachers' pedagogical practice in teaching science lessons with mobile phones, Technology, Pedagogy and Education 23(2), pp $131-150$

[23] Ekanayake S., Wishart, J.(2015). Integrating mobile phones into teaching and learning: A case study of teacher training through professional development workshop, British Journal of Educational Technology, 46(1). 